\title{
$1 \quad$ Ecosystem type shapes trophic position and omnivory in
}

2

3

4

5

6

7

$8{ }^{1}$ Departamento de Zooloxía, Xenética e Antropoloxía Física, Facultade de Bioloxía,

9 Universidade de Santiago de Compostela, Santiago de Compostela, España

$10{ }^{2}$ Department of Arctic and Marine Biology, Faculty of Biosciences, Fisheries and

11

12

13

14

15

16 Corresponding author: Javier Sánchez-Hernández (javier.sanchez@usc.es)

17

18

19

20

21 Running title: Ecosystem type shapes trophic ecology

22

\section{fishes}

Economics, UiT The Arctic University of Norway, Tromsø, Norway

Javier Sánchez-Hernández ${ }^{1}$ and Per-Arne Amundsen²

(1)




\section{Abstract}

24 The identification of patterns in ecological characteristics of organisms is a central 25 challenge in macroecology with a growing research interest. The goal of this study was 26 to establish whether patterns in trophic ecology (trophic position and omnivory) of

27 fishes can be extended to an ecosystem dimension (freshwater versus marine 28 environments), based on the premise that differences in environmental and ecological 29 conditions of aquatic ecosystems have a large influence on the feeding ecology of 30 fishes. To elucidate any relationship between trophic ecology and ecosystem type, we 31 compiled a database using a global dataset for fishes (http://www.fishbase.org). The 32 database included 5726 species distributed in 53 orders based on three common feeding 33 strategies (herbivory, filter-feeding and predatory). Trophic position and omnivory 34 increased from freshwater to marine ecosystems in filter-feeding and predatory species.

35 In herbivore species in contrast, omnivory decreased, whereas no statistically significant 36 trends were found for trophic position, which may reflect a similar diet specialisation on 37 primary producers regardless of ecosystem type. These findings suggest that ecosystem 38 type has a marked effect on trophic position and omnivory in fishes, but the impact 39 depends on the type of feeding strategy. Prey availability, inherent feeding traits linked 40 to the phylogenetic relatedness of species, ontogenetic effects, spatial variability 41 (habitat related factors) and body size are considered as responsible factors for the 42 observed patterns. Our findings demonstrate consistent patterns in trophic 43 characteristics of organisms linked to ecosystem type, and underline the usefulness of 44 fishes as model organisms to test macroecology hypotheses.

46 Keywords: aquatic systems, FishBase, global datasets, macroecology, trophic ecology 


\section{Table of contents:}

49 Introduction

50 Methods

51 Ecosystem type

$52 \quad$ Feeding strategies

53 Main food type

54 Habitat

55 Geographic range

56 Phylogenetic-taxonomic classification

57 Trophic position and omnivory index

58 Body size

59 Compiled dataset

$60 \quad$ Statistics

$61 \quad$ Results

62 Discussion

63 Acknowledgements 


\section{Introduction}

65 The assessment of the trophic position of animals has been a keystone for the 66 understanding of food web complexity and functioning (Hussey et al., 2014). Shifts in 67 trophic position of animals have been associated with several abiotic and biotic factors 68 such as prey availability, diet composition, body size, hydrologic stability, ecosystem

69 area and environmental change (e.g., Stergiou \& Karpouzi, 2002; Sabo, Finlay, 70 Kennedy, \& Post, 2010; Romanuk, Hayward, \& Hutchings, 2011; Eloranta et al., 2015).

71 A recent study focussed on an anadromous fish species Atlantic salmon (Salmo salar, 72 Salmonidae) revealed a clear increasing gradient in trophic position from freshwater to 73 marine ecosystems using stable isotopes (Dixon, Power, Dempson, Sheehan, \& Chaput, 74 2012). The proposed mechanism driving this gradient is the distinct feeding shift from 75 the freshwater to the marine environment, which leads to a marked change in the range 76 of carbon and nitrogen sources utilised by the species with a concomitant increase in its 77 trophic position (Dixon et al., 2012). The diet composition determines the trophic 78 position of animals with primary and intermediate consumers being located at lower 79 trophic levels than top predators (DeNiro \& Epstein, 1978; McCutchan, Lewis, Kendall, $80 \&$ McGrath, 2003). Consequently, the trophic position of animals summarises their 81 functional role in the trophic network of the ecological community and their specific 82 contribution to the energy flow pathways of the ecosystem (Post, 2002; Hussey et al., 83 2014).

85 Past studies have connected trophic position of fishes with aspects of trophic ecology theory such as for example ontogenetic trajectories and dietary habits, highlighting that 87 trophic position typically increases with body size (Romanuk et al., 2011; Sánchez88 Hernández, Eloranta, Finstad, \& Amundsen, 2017, but see Layman, Winemiller, 
89 Arrington, \& Jespen, 2005), and increases from herbivorous to carnivorous species

90 (Stergiou \& Karpouzi, 2002). Additionally, species of the same order or family are

91 expected to have similar dietary habits compared to species that are phylogenetically

92 more distant (German \& Horn, 2006). Thus, the exploration of patterns in trophic

93 ecology across ecosystem type should include a framework that includes the interplay

94 among dietary habits, body size and phylogeny. Yet, variations in trophic position of

95 animals among different types of ecosystems are poorly explored, although some

96 notable exceptions exist (Carscallen et al., 2012; Dixon et al., 2012). Understanding the

97 ecological principles behind differences in feeding of animals among various types of

98 ecosystems is a basis for understanding food web dynamics and ecosystem functioning,

99 and thereby instrumental in the development of ecological theory (e.g., Shurin et al.,

100 2002; Shurin, Gruner, \& Hillebrand, 2006; Elser et al., 2007). Comparisons between

101 aquatic and terrestrial ecosystems have demonstrated unambiguous differences in their

102 food-web structure (see Shurin et al., 2006). Within aquatic systems, marine ecosystems

103 have traditionally been considered more productive than freshwater ecosystems (Shurin

104 et al., 2006), but freshwater and marine ecosystems are surprisingly similar in terms of

$105 \mathrm{~N}$ and P limitations (Elser et al., 2007 and references therein).

107 The commonness and importance of omnivory have drawn attention of many scientists,

108 especially in relation to aspects of ecosystem stability (Long, Bruno, \& Duffy, 2011;

109 Kratina, LeCraw, Ingram, \& Anholt, 2012; Wootton, 2017). Omnivores are

110 polyphagous, consuming many types of prey from more than one trophic level, and thus

111 having an important impact on energy flows, nutrient cycling and ecosystem

112 functioning as promoters of stability (Fagan, 1997; Covich, Palmer, \& Crowl, 1999;

113 Kratina et al., 2012). However, contemporary studies have come to differing 
114 conclusions in respect to the commonness of omnivory among ecosystem types.

115 Omnivory has traditionally been considered more common in marine systems compared

116 to both terrestrial and freshwater ecosystems (Chase, 2000; Shurin et al., 2006;

117 Thompson, Hemberg, Starzomski, \& Shurin, 2007). On the other hand, González-

118 Bergonzoni et al. (2012) concluded that the prevalence of omnivorous fish species is

119 higher in freshwater than in marine ecosystems, but with a consistent decreasing trend

120 with latitude regardless of type of ecosystem. Likewise, other researchers noted that

121 omnivory within the family Terapontidae is less frequent (in terms of number of

122 species) in marine and euryhaline environments than in freshwater systems (Davis,

123 Unmack, Pusey, Johnson, \& Pearson, 2012). Besides, omnivory in some freshwater

124 systems, such as alpine lakes, can be very high (above $80 \%$ of omnivore species), and

125 even higher or similar to marine food webs (Sánchez-Hernández, Cobo, \& Amundsen,

1262015 and references therein). However, differences in omnivory among ecosystems are

127 still under scientific debate and the factors responsible of such differences in omnivory

128 are currently unexplored, representing a topical subject for ecological research.

130 This paper explores possible differences in trophic position and omnivory of fish among

131 two main types of aquatic ecosystems (freshwater and marine environments), aiming to

132 disentangle the magnitude and direction of any ecosystem-level dissimilarities in

133 trophic ecology. Fish species represent suitable model organisms to face comparative

134 ecological studies as they are widely distributed among contrasting ecosystem

135 configurations (i.e., freshwater, brackish and marine ecosystems). Utilising data from

136 FishBase, we here present the first comprehensive study comparing trophic position and

137 omnivory of fishes among ecosystem types including a broad dataset (5726 fish species)

138 based on three common feeding strategies (herbivory, filter-feeding and predatory), 
139 main food types (plants, zooplankton, zoobenthos and nekton), spatial variability

140 (habitat and geographic range) and phylogeny (orders and families). The aim of the

141 present study was to establish whether patterns in trophic ecology (trophic position and

142 omnivory) can be extended to an ecosystem dimension. We expected an increasing

143 trend in trophic position and omnivory from freshwater to marine ecosystems related to

144 differences in their prey communities (Emery, 1978; Shurin et al., 2006; Grosberg,

145 Vermeij, \& Wainwright, 2012), testing the hypothesis that fish species having the same

146 dietary habits or phylogeny vary their trophic position and omnivory with ecosystem

147 dimension. As the marine environment could be dominated by larger-bodied fish

148 species compared to freshwater systems, we further explored whether patterns in trophic

149 ecology of fishes can be related to ecosystem-specific differences in body size. We

150 finally tested the hypothesis that changes in trophic position and omnivory across

151 ecosystems remain the same regardless of habitat and geographic range.

\section{Methods}

154 Data were retrieved from FishBase, a global database including more than 33000 fish 155 species inhabiting freshwater, brackish and marine ecosystems (Froese \& Pauly, 2017), 156 using "rFishBase" package (Boettiger, Lang, \& Wainwright, 2012). Our study addresses 157 relevant information about trophic position, omnivory, feeding habits and type of 158 ecosystem to provide comprehensive coverage of the relevant trophic and ecological 159 aspects of our analyses. Fish species were classified according to: (i) ecosystem type, 160 (ii) feeding strategies, (iii) main food type, (iv) habitat type, (v) geographic range, and 161 (vi) phylogeny (orders and families) based on the categorical typologies supplied in 162 FishBase. 


\section{Ecosystem type}

165 Concerning ecosystem types, the dataset retrieved from FishBase included fish species

166 strictly limited to freshwater, brackish and marine ecosystems. Species strictly limited

167 to brackish waters were only represented by 21 species of which just four had available

168 the complete information needed for the analyses (trophic position, omnivory and

169 feeding strategy). Hence, the low numbers of brackish water species prevented their

170 further use in this study. Species inhabiting freshwater or marine ecosystems in

171 combination to brackish ecosystems were assigned as freshwater or marine,

172 respectively. However, species inhabiting all three ecosystem types $(n=298)$ were not

173 included in the further analyses to avoid possible bias related to the nature of the data

174 uploaded to FishBase, and eliminate the risk of including biased information from only

175 one ecosystem type instead of information including all three environments.

$177 \quad$ Feeding strategies

178 FishBase includes three categories (herbivory, filter-feeding and predatory) to give a 179 general idea of the feeding strategy in fishes. Herbivorous species include different 180 species predominantly grazing on aquatic (i.e., benthic algae, macrophytes or 181 periphyton) and terrestrial plants (i.e., riparian fruits and leaves), whereas filter feeders 182 and predators typically feed on animal material. Predators hunt macrofauna (insects, 183 crustaceans, worms, cephalopods, fish, etc), whereas filter feeders forage on plankton at

184 different depths of the water column. Because diet composition of animals shapes their 185 trophic position (DeNiro \& Epstein, 1978; McCutchan et al., 2003), the three selected 186 feeding strategies may cover functional roles of fish species in the ecosystem at three 187 different food web levels: lower, intermediate and top. Herbivorous species exploiting 188 benthic sources such as algae (i.e., lower trophic taxa) reflect the lower levels of the 
189 food webs. Filter feeders are adapted to exploit particles, especially zooplankton,

190 suspended in the water column and they may reflect the intermediate levels of food

191 webs through the pelagic production pathways. Predators, which actively hunt, catch

192 and ingest animals, are typically at the top of the food web and they are commonly used

193 as sentinel species of ecosystems.

\section{Main food type}

196 Predators species were partitioned into two groups (zoobenthivore and nekton feeders)

197 according to which main food type (zoobenthos and nekton, respectively) that was 198 dominant ( $>50 \%$ contribution) in the diet of each species. Zoobenthos comprises a wide

199 variety of prey categories including many taxa of insects, crustaceans, molluscs, 200 sponges, ascidians and polychaetes. Nekton includes organisms of relatively large size

201 capable of swimming against currents (mainly fish and cephalopods). This allowed us to 202 compare two broad foraging modes (zoobenthivore and nekton feeders) between 203 ecosystem types to reveal more accurate differences in trophic ecology between 204 ecosystem configurations. In contrast, the lack of categorical breakdown of herbivory 205 (with plants as main food) and filter-feeding (with zooplankton as main food) restricted 206 the further exploration of underlying dietary patterns between ecosystem types to 207 predatory species only.

Habitat

210 Because both freshwater and marine systems encompass several habitats with 211 contrasting food availabilities and variable conditions, species were grouped in eight 212 habitat typologies: (i) bathydemersal (living and feeding on the bottom below $200 \mathrm{~m}$ ), 213 (ii) bathypelagic (living or feeding in open waters at depths between 1,000 and 4,000 
$214 \mathrm{~m}$ ), (iii) benthopelagic (living and feeding near the bottom as well as in midwaters or

215 near the surface), (iv) demersal (living on or near the bottom and feeding on benthic

216 organisms), (v) pelagic (living and feeding in the open waters), (vi) pelagic-neritic

217 (living and feeding in nearshore areas of open waters), (vii) pelagic-oceanic (living and

218 feeding in open waters beyond the continental shelf) and (viii) reef-associated (living

219 and feeding on or near coral reefs). While marine species included all habitat types

220 except the demersal, freshwater species were restricted to five of these habitat types (see

221 Appendix 1).

222

223 Geographic range

224 To guarantee that both the freshwater and marine fishes analysed are evenly distributed 225 across environments of similar temperature and environmental conditions, geographic

226 range was taken into account. All fish species were sorted into four broad geographic

227 zones or climatic domains according to its distribution, including (i) tropical, (ii)

228 subtropical (broadly located between $23.5^{\circ}$ and $35.0^{\circ}$ north or south latitude), (iii)

229 temperate (middle latitudes, spanning between the tropics and the polar regions), and

230 (iv) polar (including north of the Arctic and south of the Antarctic Circles) species.

231 Many bathydemersal and bathypelagic species show a wide geographic range including

232 several geographic zones and were assigned as cosmopolitan species (see Appendix 1).

233 When geographic range was not provided in FishBase, the geographic range was

234 assigned based upon assessments of location information or maps provided in FishBase.

236 Phylogenetic-taxonomic classification

237 As indicated in the Introduction, key components of this study such as aspects of dietary

238 habits and covariates such as body size and habitat type may all have significant 
239 associations with the phylogenetic relatedness of species (e.g., German \& Horn, 2006;

240 Romanuk et al., 2011; Davis et al., 2012). Thus, we assigned phylogeny (order and

241 family) to each species to be more accurate in our analyses. However, many of the 242 orders belonged to only one type of ecosystem, and in other cases the low numbers $(n<$

243 10) of species belonging to the same order prevented its use (see Appendix 2). In this 244 regard, we performed a comparative study of five orders (Clupeiformes, Osmeriformes, 245 Perciformes, Scorpaeniformes and Siluriformes) based on the selection criteria of a 246 minimum number of ten species (i.e., $n \geq 10$ ). Additionally, a good representation in 247 terms of species numbers of some families in both ecosystem types, allowed us also to 248 perform analyses at the family level for Clupeidae (Clupeiformes), Gobiidae 249 (Perciformes) and Ariidae (Siluriformes).

\section{Trophic position and omnivory index}

252 In FishBase, trophic position (Troph) is estimated according to Pauly \& Christensen 253 (1995) by adding 1 to the mean trophic position of each prey species in the diet (DIET

254 Table in FishBase; Palomares \& Sa-a, 2000) utilised by a species:

$$
\text { Troph }=1+\sum_{j=1}^{G} D C_{i j} \times \operatorname{Troph}_{j}
$$

where $\operatorname{Troph}_{j}$ is the fractional trophic level of prey $j, D C_{i j}$ represents the fraction of $j$ in the diet of the fish species $i$ and $G$ is the total number of prey species. Troph usually vary around 2 and 5 in herbivorous and carnivorous organisms, respectively (Pauly,

260 Trites, Capuli, \& Christensen, 1998; Froese \& Pauly, 2017). For example, if the fish 261 species $i$ shows a diet composed by, in terms of relative abundance, 50\% phytoplankton 
$262($ Troph $=1)$ and 50\% zooplankton $($ Troph $=2)$; the fish species $i$ would have Troph of

263 2.5. In this regard, there has been a continuous debate over the use of gut content 264 analysis versus stable isotopes methods for estimates of trophic position of animals 265 (e.g., Post, 2002; Rybczynski, Walters, Fritz, \& Johnson, 2008; Carscallen et al., 2012).

266 Often, gut content analyses have been criticised as being less powerful and accurate 267 than stable-isotope-based estimates of trophic position (Post, 2002). However, several 268 studies have demonstrated that estimates of trophic position based on dietary 269 observations are straightforward and highly correlated to isotope-based methods (Kline 270 \& Pauly, 1998; Carscallen et al., 2012). FishBase contains two trophic position metrics 271 (FoodTroph and DietTroph); here we relied on FoodTroph because of its higher 272 abundance of records compared to DietTroph.

273

274 The omnivory index $(O I)$ is calculated from the variance of the Troph of the consumed 275 food resources:

276

$$
O I=\sum_{j=1}^{n}\left(T L_{j}-\left(T L_{i}-1\right)\right)^{2} \times D C_{i j}
$$

277

278 where $n$ is the number of prey categories, $T L_{j}$ is the Troph of prey $j, T L_{i}$ is the trophic 279 level of predator $i$, and $D C_{i j}$ is the fraction of prey $j$ in the diet of predator $i$. The index 280 values vary from zero (when all feeding occurs at the same trophic level) to increasing 281 values with an increasing variety of Troph of the utilised prey categories. 282 
284 Since fish size is an important factor, particularly in respect to trophic position

285 (Romanuk et al., 2011), we retrieved body size information (here maximum length)

286 from FishBase. This allowed us to test whether any differences observed between 287 ecosystem types in trophic position and omnivory can be related to ecosystem-specific 288 differences in body size.

\section{Compiled dataset}

291 The final dataset consisted of data for trophic position, omnivory index, body size, 292 dietary habits (feeding strategies and main food type), habitat type, geographic range 293 and ecosystem type in 5426 species distributed in 53 orders and 387 families (Appendix

294 2). Additionally, the nature of the compiled dataset comprising several categorical 295 covariates, allowed us to run two comparative approaches, including coarse and finer 296 scaled dietary habits. The coarse-scaled approach was covered by using a broad fish 297 classification into the above-described feeding strategies. On the other hand, the 298 categorical breakdown of predatory species into two dietary groups (i.e., zoobenthivore 299 and nekton feeders) together with the phylogenetic considerations and spatial variability 300 (habitat and geographic range) enabled a finer treatment of the dataset. The low 301 sampling size $(n<5$; Appendix 1$)$ in freshwater species inhabiting bathydemersal and 302 pelagic-neritic habitats prevented its use for the comparative approach. All data used in 303 this study are available from FishBase (see Data accessibility).

\section{Statistics}

306 Statistical analyses and graphical outputs were performed using R 3.4.2 (R Core Team, 307 2017). Shapiro-Wilk tests indicated non-normality in the data. To identify the possible 308 differences in trophic ecology (trophic position and omnivory) and body size of fishes 
309 between ecosystem types, we used the nonparametric Mann-Whitney-Wilcoxon test for

310 two independent groups of samples. This comparative approach was repeated for coarse

311 (feeding strategies) and finer (main food type, phylogeny, habitat and geographic range)

312 scale dietary habits. Significance levels were adjusted by applying the Bonferroni

313 method using the "dunn.test” package (Dinno, 2017).

315 Because the FishBase data relies on the original data uploaded and may be biased

316 towards frequently studied or economically important species, there is a need to control

317 possible data biases. Statistical procedures carried out in this study were aimed to

318 control these limitations by using finer scale dietary habits and mixed modelling with

319 random effects. If the outcomes remain similar across finer scale dietary habits and

320 spatial covariates, the robustness of our findings regardless of possible biases is

321 supported. In addition, random effects control for heterogeneity and variation

322 attributable to different studies being conducted by different researchers, and can reduce

323 publication bias (Zuur, Ieno, Walker, Saveliev, \& Smith, 2009; Stanley, Doucouliagos,

324 \& Ioannidis, 2017; Gurevitch, Koricheva, Nakagawa, \& Stewart, 2018). Because our

325 data did not meet normality and hence the assumptions for linear regression models

326 (Zuur et al., 2009), we used generalised additive mixed models (GAMMs) to test

327 whether ecosystem type affects the trophic ecology of fishes using the "mgcv" package

328 (Wood, 2017). We modelled each dependent variable separately (i.e., one model for

329 trophic position and another for omnivory) with ecosystem type as smoothed term, and

330 adjusted for phylogenetic effects by adding order as a random intercept in the GAMMs.

331 Thus, by introducing order as a random factor, we model between-order variation in diet

332 composition resulting from variables not possible to consider in the current study such

333 as e.g. morphological constrains (gape size, gill raker length and interraker spacing) and 
334 variation and potential biases attributable to a plausible non-random selection of species

335 uploaded to FishBase (e.g., frequently studied or economically important species are

336 more likely to be represented). Additionally, to account for dietary habits and spatial

337 effects in our models, feeding strategies, main food type, habitat type and geographic

338 range were also included as smoothed terms. Thus, the full model consisted of one

339 predictor variable and five smooth terms $[\sim$ body size $+\mathrm{s}($ ecosystem $)+\mathrm{s}($ feeding

340 strategies $)+s($ main food type $)+s($ habitat $)+s($ geographic range $)]$ with order as random

341 factor. The smooth terms represent categorical variables with data hierarchically

342 structured (i.e., data structure organised in several categories). GAMMs and model

343 selection was done by model comparison using the "MuMIn" package (Bartoń, 2017).

344 Using a model selection method (Burnham \& Anderson, 2002), we ranked the candidate

345 models according to the Akaike information criterion (AIC, the best model being the

346 one with the lowest AIC values). Residuals of the final selected models were visually

347 inspected for deviations from normality and heteroscedasticity without finding evidence

348 for any violation of model assumptions (see Appendix 3). Analyses were considered

349 statistically significant at $p<0.05$.

\section{$351 \quad$ Results}

352 Overall, Troph tended to increase from freshwater to marine ecosystems (Figure 1), but 353 statistically significant differences were only found in eleven out of nineteen cases (see

354 Table 1). Specifically, ecosystem type shaped Troph in filter-feeding ( $\mathrm{W}=27039, p=$ $3550.001)$, predatory $(\mathrm{W}=1017400, p<0.001)$ and zoobenthivore $(\mathrm{W}=465690, p<$ 356 0.001) species, with higher values in marine than in freshwater ecosystems. Trophic 357 position was also significantly higher in marine species of Osmeriformes $(\mathrm{W}=98, p=$ $3580.022)$ and Scorpaneiformes $(\mathrm{W}=523, p=0.025)$, but higher in freshwater species of 
359 Gobiidae $(\mathrm{W}=718.5, p=0.006)$. Except for polar species $(\mathrm{W}=155, p=0.671)$, the

360 higher Troph values observed in marine species compared to freshwater species were

361 remained across habitat types and geographic range (Figure 2 and Table 1). All

362 statistically significant tests remained significant after Bonferroni correction.

363

364 Also omnivory increased from freshwater to marine ecosystems in filter-feeding ( $\mathrm{W}=$

$36528416, p=0.012)$, predatory $(\mathrm{W}=1183600, p<0.001)$, zoobenthivore $(\mathrm{W}=574290, p$

$366<0.001)$, benthopelagic $(\mathrm{W}=61054, p<0.001)$, demersal $(\mathrm{W}=241040, p=0.001)$,

367 subtropical $(\mathrm{W}=27927, p<0.001)$ and temperate $(\mathrm{W}=44672, p<0.001)$ species

368 (Figures 1 and 2), whereas the direction of increase was the inverse (i.e., from marine to

369 freshwater ecosystems $)$ in herbivorous species $(\mathrm{W}=39480, p=0.036)$, nekton-feeders

$370(\mathrm{~W}=128920, p<0.001)$ and Perciformes $(\mathrm{W}=717230, p<0.001)$. All statistically

371 significant tests remained significant after Bonferroni correction (Table 1).

372

373 The best model configurations for Troph and omnivory highlighted the importance of 374 ecosystem type and dietary habits (i.e., feeding strategies and main food type) to 375 understand the observed patterns in ecological characteristics of fish species (Table 2).

376 Habitat type and body size (here maximum size) were influential variables of the most 377 satisfactory model for omnivory, whereas geographic range and body size had a 378 substantial influence on trophic position (see Appendix 4 for summary table of the 10 379 best model simulations). Thus, body size may be a contributing factor for the observed 380 patterns across the ecosystem dimension, but again this impact largely depended on the 381 dietary habits of species as Troph and omnivory seemed to be strongly linked to body 382 size only in predatory, zoobenthivore, benthopelagic, demersal, subtropical and 383 temperate species as well as in Scorpaneiformes (see Table 1). Moreover, despite the 
384 higher Troph revealed in marine compared to freshwater species of Osmeriformes, the

385 species within this order tended to be larger in freshwater ecosystems $(\mathrm{W}=61.5, p<$

386 0.001). The model configurations showed the ubiquitous importance of ecosystem 387 differences in dietary habits (i.e., feeding strategy and main food type) to understand 388 differences in trophic characteristics of organisms across ecosystems (Table 2 and 389 Appendix 4).

\section{Discussion}

392 Ecosystem type had a marked effect on trophic position and omnivory in fishes, but the 393 impact depended on the type of feeding strategy and inherent food preferences linked to 394 the phylogenetic relatedness of species. More specifically, trophic position and 395 omnivory revealed an increasing trend from freshwater to marine ecosystems in both 396 filter-feeding and predatory species, as well as within some specific taxonomic groups 397 (Osmeriformes and Scorpaeniformes), whereas a decreasing trend was found for 398 herbivory species and Gobiidae. These trends seemed partly to be related to ecosystem399 specific differences in body size. However, the impact largely depended on the type of 400 feeding strategy as body size was an important factor for ecosystem differences in the 401 trophic ecology of predatory species (especially those with zoobenthos as main food) 402 and Scorpaneiformes, whereas less effects of body size was seen in filter-feeding and 403 herbivory species and also within most orders as indicated in Table 1. The increasing 404 trend from freshwater to marine ecosystems in trophic position and omnivory remained 405 the same regardless of spatial variability (habitat and geographic range). In line with 406 macroecological theory, the revealed patterns in trophic position and omnivory of 407 aquatic animals between ecosystem type may in part also result from a greater 
408 production and biodiversity in marine compared to freshwater ecosystems (Shurin et al.,

409 2006; Grosberg et al., 2012).

410

411 Our hypothesis that the trophic position of fishes would be associated with ecosystem

412 type was partially supported. Trophic position increased from freshwater to marine

413 ecosystems in filter-feeding, predatory (only statistically significant in those species

414 feeding mainly on zoobenthos), benthopelagic, demersal, tropical, subtropical and

415 temperate species, and in Osmeriformes and Scorpaneiformes, but not in herbivory

416 species and most other taxonomic classifications (i.e., six out of eight). This suggests

417 that species grazing on benthic resources, most typically algae, may have similar trophic

418 levels regardless of ecosystem type (France, 1996). We posit that the similarity in

419 trophic level of herbivore species between ecosystem types may be a result of these

420 species being highly specialised on consuming primary producers and thus having a

421 lower ability to utilise prey at other (i.e., higher) trophic levels. This is strongly

422 supported by their low degree of omnivory, which thus locates them at the lowest

423 consumer position in all ecosystem types.

425 Because energy transfer efficiencies can vary among ecosystems (see Pauly \& 426 Christensen, 1992), the response to changes in prey availability among ecosystems and 427 geographic territories within the same ecosystem is central in many theories of aquatic 428 ecosystem functioning and dynamics (Ives, Cardinale, \& Snyder, 2005; Dixon et al., 429 2012; Schmitz, Miller, Trainor, \& Abrahms, 2017). Our findings corroborate this view 430 as a clear increasing gradient in trophic position was found between freshwater and 431 marine ecosystems in filter-feeding and predatory species. Our analyses also provide 432 solid evidence that the increasing gradient in trophic position between freshwater and 
433 marine species is maintained at a more localised range (here habitat and geographic 434 range). It is reasonable to posit that this shift from low to high trophic positions between 435 aquatic ecosystems is a response to changes in prey availability, which is usually more 436 diverse, productive and abundant in the marine systems (Shurin et al., 2006; Grosberg et 437 al., 2012). Trophic position of fish species is very variable among species and 438 commonly range from 2.0 to 5.29 (Vander Zanden \& Rasmussen, 1996; Vander 439 Zanden, Cabana, \& Rasmussen, 1997; Stergiou \& Karpouzi, 2002; Romanuk et al., 440 2011), being positively related to maximum body size of the species (Romanuk et al., 441 2011). Our results provide important advances on these previous studies by contributing 442 new evidence of the importance of ecosystem type and type of feeding strategy to 443 understand the variation in trophic position of fish species. Noteworthy, ecosystem444 specific differences in body size, most likely associated with morphological constraints 445 (i.e., gape limitation), appear to play a key role in determining trends in trophic position 446 across ecosystems in predatory species, but not in filter-feeding and herbivory species. 447 An important mechanism driving this trend might be piscivorous behaviour. Piscivory 448 leads to increases in trophic position and typically a specialisation in resource use 449 (Sánchez-Hernández et al., 2017 and references therein). Additionally, it seems like the 450 proportion of piscivorous species is greater in marine than in freshwater systems 451 (Winemiller \& Leslie, 1992). Opposite, cannibalism has been assumed to be more 452 common in freshwater than in marine systems (Pereira, Keppeler, Agostinho, \& 453 Winemiller, 2017a), but a recent review suggests that the degree of cannibalism is 454 similar between marine and freshwater fishes (Pereira, Agostinho, \& Winemiller, 455 2017b). Thus, our findings and those of other authors (e.g., Winemiller \& Leslie, 1992), 456 indicate that the capacity to forage on fish and other nekton resources seems to be more 457 common in marine than in freshwater predators as indicated here by their higher trophic 
458 position. That said, we postulate that the positive trend in trophic position from

459 freshwater to marine ecosystems by predatory species, apparently shaped by body size,

460 is highly linked to piscivorous behaviour since piscivory drives an increase in trophic 461 position and increases over the ontogeny (e.g., Mittelbach \& Persson, 1998; Sánchez-

462 Hernández et al., 2017). Additionally, we posit that the unexpectedly higher trophic

463 position of Gobiidae in the freshwater environment is related to phylogenetic-related

464 differences in dietary habits across ecosystem, with nekton feeders in this taxon being 465 more prevalent in freshwater environments $(15 \%$ and $1.6 \%$ in freshwater and marine, 466 respectively), and consequently responsible of its overall higher trophic position. This 467 underpins that differences in inherent dietary habits linked to the phylogenetic 468 relatedness of species across type of ecosystems may be a keystone for understanding 469 patterns in trophic position of fishes. Additional work will be needed to explore whether 470 or not similar patterns can be generalised to other aquatic consumers.

472 Previous studies have reached contrasting conclusions in respect to the prevalence of 473 omnivory in different aquatic ecosystems, but the present study confirms that the 474 importance of omnivory can be extended to an ecosystem dimension (i.e., higher in 475 marine environments) and our findings also provide novel insight to the causes that lead 476 to differences in omnivory levels across ecosystems. Hence, the revealed patterns in 477 omnivory of fishes corroborate the hypothesis that ecosystem dimension shape the 478 prevalence of omnivory in aquatic consumers. With a few exceptions (nekton-feeders, 479 herbivory species, tropical species, polar species and Perciformes), omnivory increased 480 from freshwater to marine ecosystem. Thus, our study largely supports previous 481 findings on the notion that omnivory is more prevalent in marine compared to both 482 terrestrial and freshwater ecosystems (Chase, 2000; Shurin et al., 2006; Thompson et 
483 al., 2007). However, recent studies have shown that the prevalence of omnivorous 484 species seems to be higher in freshwater than in marine ecosystems (González485 Bergonzoni et al., 2012; Sánchez-Hernández et al., 2015). These are seemingly 486 contradictory standpoints. The first consideration encapsulates that the variety of trophic 487 positions of prey categories consumed by fishes (henceforth "degree of omnivory") is 488 higher in marine than in freshwater ecosystems, and the second that the relative 489 proportion of species that can exploit resources at multiple trophic levels is actually 490 greater in freshwater ecosystems. We suggest that these apparent contradictions can be 491 resolved if the nature of omnivory by fish species, the prey availability and the 492 ontogenetic dietary shifts of species are taken into account. That is, although the number 493 or prevalence of omnivore species can be higher in freshwater, the degree of omnivory 494 is higher in marine species, most likely because of a higher plasticity of marine species 495 to exploit available resources at a higher number of trophic levels compared to 496 freshwater species. This can clearly be illustrated through the example of filter-feeding 497 fish species. Although these species may select food particles suspended in the water 498 (seston) by size based on morphological constrains (gape size, gill raker length and 499 interraker spacing), they do usually not select by prey type (Gerking, 1994). It should be 500 kept in mind that in contrast to marine systems, freshwater systems contain 501 comparatively simple communities of organisms suspended in the water. More 502 precisely, food resources available for filter feeders are limited to zooplankton in 503 freshwater systems, whereas available resources are much wider in the marine systems, 504 including also taxa other than common zooplankton (i.e., copepods and cladocerans), 505 such as krill, worms, mollusks and fish larvae (Garrido et al., 2008; Costalago, Garrido, $506 \&$ Palomera, 2015). It is possible that this broader variety of food resources available in 
507 the marine environment is connected to the observed positive trends in omnivory and

508 trophic position from freshwater to marine ecosystems by fishes.

510 On the other hand, the differences in ontogenetic dietary shifts between ecosystems can

511 be vital to understand the magnitude and direction of any ecosystem-level dissimilarities

512 in omnivory. Taking as example the nekton feeders, we accept the view that the nature

513 of the ontogenetic dietary shifts is responsible for their higher omnivory in freshwater

514 ecosystems. We posit that the occurrence of several distinct ontogenetic dietary shifts

515 might be less plausible in marine predator species because they usually switch to

516 piscivory very early in the ontogeny or undergo smooth dietary shifts, such as many

517 species of e.g. Squaliformes, tunas (Thunnus spp., Scombridae) or anglerfish (Lophius

518 spp., Lophiidae) (e.g., Preciado, Velasco, Olaso, \& Landa, 2006; Reglero, Urtizberea,

519 Torres, Alemany, \& Fiksen, 2011). In contrast, freshwater nekton feeders may appear to

520 undergo several steps before they become piscivorous, thereby consuming prey types

521 from more trophic levels than marine species. From the FishBase data, this is the case

522 for many freshwater predators such as pikeperch (Sander lucioperca, Percidae) and

523 some salmonids, who initially prey upon zooplankton and zoobenthos, but later switch

524 to fish. Similar as for trophic position, it is reasonable to posit that ecosystem type

525 impacts omnivory in fishes in response to changes in prey availability across

526 ecosystems. Factors other than prey availability, such as inherent food preferences and

527 ontogenetic dietary shifts may also have a major influence on omnivory in fishes, and

528 thus the differences that occur between ecosystems.

530 As already pointed out, a caveat should be exercised regarding conclusions from 531 analyses of dietary data uploaded to FishBase. These may suffer limitations from 
532 heterogeneity and other data issues due to possible biases towards (i) frequently studied 533 or economically important species and (ii) uneven sampling effort across the different 534 dietary habits and spatial variability (e.g., habitat and geographic related factors), which 535 may hinder our ability to identify gradients across ecosystems. Here, these potential 536 biases were addressed by implementing analytical approaches using random effects 537 (Zuur et al., 2009; Stanley et al., 2016; Gurevitch et al., 2018; see the Statistics section). 538 In addition, the key conclusions of this study (i.e., trophic position and omnivory 539 increase from freshwater to marine species) broadly remained the same across habitat, 540 geographic range and finer scaled dietary habits (main food type and phylogeny), 541 suggesting a strong robustness of our findings regardless of any possible biases in the 542 data archive. Still, there are some limitations and considerations that need to be 543 acknowledged when using the available FishBase dataset as in the present study. In fact, 544 one of the main disadvantages of this approach could be the lack of a comprehensive 545 database covering ontogenetic and seasonal effects on dietary habits of fish species as 546 was thoroughly highlighted by Stergiou \& Karpouzi (2002). It seems that in FishBase, 547 ontogenetic dietary shifts are well covered for some species, whereas information about 548 ontogenetic trajectories is limited for other species. A good representation of these 549 dietary shift in FishBase can e.g. be found in European perch (Perca fluviatilis, 550 Percidae), which is known for showing characteristic ontogenetic dietary shifts with 551 juveniles primarily feeding upon zooplankton before switching to benthic invertebrates 552 and later to small and subsequently to large fish prey (e.g., Amundsen et al., 2003). In 553 contrast, many omnivorous and herbivorous species undergo ontogenetic dietary shifts 554 from utilising animal resources to the comprehensive use of vegetal resources (plants 555 and detritus) (e.g., Drewe, Horn, Dickson, \& Gawlicka, 2004; Reckendorfer et al., 2011; 556 Sánchez-Hernández \& Cobo, 2012), which, in turn, might not be well covered in 
557 FishBase. For example, the Common nase (Chondrostoma nasus, Cyprinidae), is in

558 FishBase considered as a strict herbivore species, but studies have shown that this

559 species rather should be considered as a facultative herbivory species with ontogenetic

560 dietary shifts that also include animal resources in the diet early in the ontogeny

561 (Reckendorfer et al., 2011). Thus, while trophic position and omnivory seem to be

562 accurately estimated in FishBase for many species undergoing ontogenetic dietary

563 shifts, the generic lists of all dietary items included in FishBase may for many other

564 uncommon and unstudied species not fully cover the ontogenetic dietary effects.

565 Another limiting factor for the FishBase estimation of trophic ecology (trophic position

566 and omnivory) could be related to the indices used for the expression of diet

567 composition data (e.g., numeric, volumetric, gravimetric, frequency of occurrence, etc).

568 As previously highlighted by Stergiou \& Karpouzi (2002), frequency of occurrence and

569 numerical data are not good indicators of diet because they provide little information

570 about the relative amount of each prey category present in the stomach or the

571 information may be biased according to the size of the prey items, respectively.

572 Although FishBase aims only to use quantitative reports of diet composition data 573 (percentage of volume or weight) (see The DIET Table in FishBase; Palomares \& Sa-a, 574 2000), more effort needs to be paid to make such diet data of poorly studied species 575 available in order to provide more accurate measures of their trophic position and 576 degree of omnivory. Because the data used in this study depends on the original dietary 577 data uploaded to FishBase, the revealed patterns might potentially be biased from the 578 inclusion of estimates of trophic position and omnivory that are not covering seasonal 579 and ontogenetic effects for some fish species. Additionally, the dataset used in this 580 study was not equally represented across habitats and phylogeny, which may impose a 581 limitation to explore ecosystem changes in trophic position and omnivory. Yet, the 
582 increasing trend from freshwater to marine ecosystems in trophic position and omnivory

583 was homogeneous regardless of habitat, geographic range and phylogeny, underlining

584 the replicability of our key findings and thus supporting their robustness regardless of 585 any possible biases that may occur in the used dataset. Hence, despite these potential 586 problems, the promising results of this study encourage the extension of this approach

587 by using data from different sources and combining stomach and isotope based methods 588 in order to improve the robustness and reliability of the used dataset and thereby 589 enhance the exploration of macroecological questions in trophic ecology.

591 In conclusion, ecosystem type evidently shapes trophic position and omnivory in fishes, 592 but the magnitudes of their effects are often quite variable depending on the type of 593 feeding strategy (here herbivory, filter-feeding and predatory) and the resource 594 preferences linked to the phylogenetic relatedness of species. Changes with ecosystem 595 type were less pronounced in herbivore species as they are specialised on primary 596 producers and thus to a small extent omnivorous, which, in turn, results in the same 597 basal trophic position among ecosystems. The study provides novel insight to 598 macroecological theory by demonstrating patterns in trophic characteristics of 599 organisms across ecosystems and identifying the most influential drivers for trophic 600 position and omnivory of fishes.

601

\section{Acknowledgements}

603 We appreciate the constructive comments from four anonymous reviewers, which 604 considerably improved the quality of the initial submission. Javier Sánchez-Hernández 605 was supported by a postdoctoral grant from the Galician Plan for Research, Innovation, 606 and Growth (Plan I2C, Xunta de Galicia). 


\section{References}

608 Amundsen, P.-A., Bøhn, T., Popova, O. A., Staldvik, F. J., Reshetnikov, Y. S., 609 Kashulin, N. A., \& Lukin, A. (2003). Ontogenetic niche shifts and resource 610 partitioning in a subarctic piscivore fish guild. Hydrobiologia, 497, 109-119. 611 doi: $10.1023 / \mathrm{A}: 1025465705717$

612 Bartoń, K. (2017). MuMIn: Multi-Model Inference. R package version 1.40.0. 613 https://CRAN.R-project.org/package=MuMIn (accessed 25 May 2018).

614 Boettiger, C., Lang, D. T., \& Wainwright, P. C. (2012). rfishbase: exploring, 615 manipulating and visualizing FishBase data from R. Journal of Fish Biology, 81, 616 2030-2039. doi: 10.1111/j.1095-8649.2012.03464.x

617 Burnham, K. P., \& Anderson, D. R. (2002). Model Selection and Multimodel Inference: 618 A Practical Information-Theoretical Approach (2nd Edition). New York, $619 \quad$ Springer-Verlag.

620 Carscallen, W. M. A., Vandenberg, K., Lawson, J. M., Martinez, N. D., \& Romanuk, T. 621 N. (2012). Estimating trophic position in marine and estuarine food webs. $622 \quad$ Ecosphere, 3, 25. doi: 10.1890/ES11-00224.1

623 Chase, J. M. (2000). Are there real differences among aquatic and terrestrial food webs? 624 Trends in Ecology \& Evolution, 15, 408-412. doi: 10.1016/S0169$625 \quad 5347(00) 01942-X$

626 Costalago, D., Garrido, S., \& Palomera, I. (2015). Comparison of the feeding apparatus 627 and diet of European sardines Sardina pilchardus of Atlantic and Mediterranean 628 waters: ecological implications. Journal of Fish Biology, 86, 1348-1362. doi: 629 $10.1111 / \mathrm{jfb} .12645$ 
630 Covich, A. P., Palmer, M. A., \& Crowl, T. A. (1999). The role of benthic invertebrate species in freshwater ecosystems. Bioscience, 49, 119-128. doi: $10.2307 / 1313537$

633 Davis, A. M., Unmack, P. J., Pusey, B. J., Johnson, J. B., \& Pearson, R. G. (2012). 634 Marine-freshwater transitions are associated with the evolution of dietary 635 diversification in terapontid grunters (Teleostei: Terapontidae). Journal of 636 Evolutionary Biology, 25, 1163-1179. doi: 10.1111/j.1420-9101.2012.02504.x

637 DeNiro, M. J., \& Epstein, S. (1978). Influence of diet on the distribution of carbon 638 isotopes in animals. Geochimica et Cosmochimica Acta, 42, 495-506. doi: 10.1016/0016-7037(78)90199-0

640 Dinno, A. (2017). dunn.test: Dunn's Test of Multiple Comparisons Using Rank Sums. R 641 package version 1.3.5. https://CRAN.R-project.org/package=dunn.test (accessed 25 May 2018).

643 Dixon, H. J., Power, M., Dempson, J. B., Sheehan, T. F., \& Chaput, G. (2012). 644 Characterizing the trophic position shift in Atlantic salmon (Salmo salar) from 645 freshwater to marine life-cycle phases using stable isotopes. ICES Journal of 646 Marine Science, 69, 1646-1655. doi: 10.1093/icesjms/fss122

647 Drewe, K. E., Horn, M. H., Dickson, K. A., \& Gawlicka, A. (2004). Insectivore to 648 frugivore: ontogenetic changes in gut morphology and digestive enzyme activity 649 in the characid fish Brycon guatemalensis from Costa Rican rainforest streams. 650 Journal of Fish Biology, 64, 890-902. doi: 10.1111/j.1095-8649.2004.0357.x

651 Emery, A. R. (1978). The basis of fish community structure: marine and freshwater 652 comparisons. Environmental Biology of Fishes, 3, 33-47. doi: 653 10.1007/BF00006307 
654 Eloranta, A. P., Kahilainen, K. K., Amundsen, P.-A., Knudsen, R., Harrod, C., \& Jones,

655

656

657

658

659

660

661

662

663

664

665

666

667

668

669

670

671

672

673

674

675

676

677

678

R. I. (2015). Lake size and fish diversity determine resource use and trophic position of a top predator in high-latitude lakes. Ecology and Evolution, 5, 1664-1675. doi: 10.1002/ece3.1464

Elser, J. J., Bracken, M. E. S., Cleland, E. E., Gruner, D. S., Harpole, W. S., Hillebrand, H., ... Smith J. E. (2007). Global analysis of nitrogen and phosphorus limitation of primary producers in freshwater, marine and terrestrial ecosystems. Ecology Letters, 10, 1135-1142. doi: 10.1111/j.1461-0248.2007.01113.x

Fagan, W. F. (1997). Omnivory as a stabilizing feature in natural communities. The American Naturalist, 150, 554-567. doi: 10.1086/286081.

France, R. L. (1996). Stable isotopic survey of the role of macrophytes in the carbon flow of aquatic foodwebs. Vegetatio, 124, 67-72. doi: 10.1007/BF00045145

Froese, R., \& Pauly, D. (2017). FishBase. World Wide Web electronic publication. www.fishbase.org, version (10/2017).

Garrido, S., Ben-Hamadou, R., Oliveira, P. B., Cunha, M. E., Chícharo, M. A., \& van der Lingen, C.D. (2008). Diet and feeding intensity of sardine Sardina pilchardus: correlation with satellite-derived chlorophyll data. Marine Ecology Progress Series, 354, 245-256. doi: 10.3354/meps07201

Gerking, S. D. (1994). Feeding Ecology of Fish. San Diego, Academic Press.

German, D. P., \& Horn, M. H. (2006). Gut length and mass in herbivorous and carnivorous prickleback fishes (Teleostei: Stichaeidae): ontogenetic, dietary, and phylogenetic effects. Marine Biology, 148, 1123-1134. doi: 10.1007/s00227005-0149-4

González-Bergonzoni, I., Meerhoff, M., Davidson, T. A., Teixeira de Mello, F., Baattrup-Pedersen, A., \& Jeppesen, E. (2012). Meta-analysis shows a consistent 

and strong latitudinal pattern in fish omnivory across ecosystems. Ecosystems, 15, 492-503. doi: 10.1007/s10021-012-9524-4

681 Grosberg, R. K., Vermeij, G. J., \& Wainwright, P. C. (2012). Biodiversity in water and 682 on land. Current Biology, 22, R900-3. doi: 10.1016/j.cub.2012.09.050

Gurevitch, J., Koricheva, J., Nakagawa, S., \& Stewart, G. (2018). Meta-analysis and the 684 science of research synthesis. Nature, 555, 175-182. doi: 10.1038/nature25753

Hussey, N. E., MacNeil, M. A., McMeans, B. C., Olin, J. A., Dudley, S. F. J., Cliff, G. 687 C., ... Fisk, A. T. (2014). Rescaling the trophic structure of marine food webs. Ecology Letters, 17, 239-250. doi: 10.1038/nature25753

Ives, A. R., Cardinale, B. J., \& Snyder, W. E. (2005). A synthesis of subdisciplines: 689 predator-prey interactions, and biodiversity and ecosystem functioning. Ecology Letters, 8, 102-116. doi: 10.1111/j.1461-0248.2004.00698.x

Kline, T. C., \& Pauly, D. (1998). Cross-validation of trophic level estimates from a mass-balance model of Prince William Sound using $15 \mathrm{~N} / 14 \mathrm{~N}$ data. In T. J. Quinn, F. Funk, J. Heifetz, J. N. Ianelli, J. E. Powers, J. F. Schweigert, P. J.

696 Kratina, P., LeCraw, R. M., Ingram, T., \& Anholt, B. R. (2012). Stability and 697 persistence of food webs with omnivory: Is there a general pattern? Ecosphere,

699 Layman, C. A., Winemiller, K. O., Arrington, D. A., \& Jespen, D. B. (2005). Body size 700 and trophic position in a diverse tropical food web. Ecology, 86, 2530-2535. doi: $10.1890 / 04-1098$ 
702 Long, Z. T., Bruno, J. F., \& Duffy, J. E. (2011). Food chain length and omnivory 703 determine the stability of a marine subtidal food web. Journal of Animal $704 \quad$ Ecology, 80, 586-594. doi: 10.1111/j.1365-2656.2010.01800.x

705 McCutchan, J. H., Lewis, W. M., Kendall, C., \& McGrath, C. C. (2003). Variation in 706 trophic shift for stable isotope ratios of carbon, nitrogen, and sulfur. Oikos, 102, 707 378-390. doi: 10.1034/j.1600-0706.2003.12098.x

708 Mittelbach, G. G., \& Persson, L. (1998). The ontogeny of piscivory and its ecological 709 consequences. Canadian Journal of Fisheries and Aquatic Sciences, 55, 1454710 1465. doi: $10.1139 / \mathrm{f} 98-041$

711 Palomares, M. L. D., \& Sa-a, P. (2000). The DIET Table. In R. Froese \& D. Pauly 712 (Eds.), FishBase 2000. Concepts, Design and Data Sources (pp. 193-196.). 713 Philippines: ICLARM.

714 Pauly, D., \& Christensen, V. (1995). Primary production required to sustain global 715 fisheries. Nature, 374, 255-257. doi: 10.1038/374255a0

716 Pauly, D., Trites, A. W., Capuli, E. V., \& Christensen, V. (1998). Diet composition and 717 trophic levels of marine mammals. ICES Journal of Marine Science, 55, 467$718 \quad$ 481. doi: $10.1006 /$ jmsc. 1997.0280

719 Pereira, L. S., Keppeler, F. W., Agostinho, A. A., \& Winemiller, K. O. (2017a). Is there 720 a relationship between fish cannibalism and latitude or species richness? PLoS $721 \quad$ One, 12, e0169813. doi: 10.1371/journal.pone.0169813

722 Pereira, L. S., Agostinho, A. A., \& Winemiller, K. O. (2017b). Revisiting cannibalism 723 in fishes. Reviews in Fish Biology and Fisheries, 27, 499-513. doi: $724 \quad 10.1007 /$ s11160-017-9469-y

725 Post, D. M. (2002). Using stable isotopes to estimate trophic position: models, methods, 726 and assumptions. Ecology, 83, 703-718. doi: 10.2307/3071875 
727 Preciado, I., Velasco, F., Olaso, I., \& Landa, J. (2006). Feeding ecology of black

728 anglerfish Lophius budegassa: seasonal, bathymetric and ontogenetic shifts.

729 Journal of the Marine Biological Association of the UK, 86, 877-884. doi:

$730 \quad 10.1017 / \mathrm{S} 0025315406013816$

731 R Core Team, (2017). R: A Language and Environment for Statistical Computing. R

732 Foundation for Statistical Computing, Vienna, Austria. Available at:

733 http://www.R-project.org/ (accessed 25 May 2018).

734 Reckendorfer, W., Keckeis, H., Tiitu, V., Winkler, G., Zornig, H., \& Schiemer, F.

735 (2001). Diet shifts in 0+ nase, Chondrostoma nasus: Size-specific differences

736 and the effect of food availability. Archiv für Hydrobiologie, 135, 425-440. doi:

$737 \quad 10.1127 / \mathrm{lr} / 12 / 2001 / 425$

738 Reglero, P., Urtizberea, A., Torres, A. P., Alemany, F., \& Fiksen, Ø. (2011).

739 Cannibalism among size classes of larvae may be a substantial mortality 740 component in tuna. Marine Ecology Progress Series, 433, 205-219. doi:

$741 \quad 10.3354 / \operatorname{meps} 09187$

742 Romanuk, T. N., Hayward, A., \& Hutchings, J. A. (2011). Trophic level scales 743 positively with body size in fishes. Global Ecology and Biogeography, 20, 231744 240. doi: $10.1111 /$ j.1466-8238.2010.00579.x

745 Rybczynski, S. M., Walters, D. M., Fritz, K. M., \& Johnson, B. R. (2008). Comparing 746 trophic position of stream fishes using stable isotope and gut contents analyses. 747 Ecology of Freshwater Fish, 17, 199-206. doi: 10.1111/j.1600$748 \quad$ 0633.2007.00289.x

749 Sabo, J. L., Finlay, J. C., Kennedy, T., \& Post, D. M. (2010). The role of discharge 750 variation in scaling of drainage area and food chain length in rivers. Science, 751 330, 965-967. doi: 10.1126/science.1196005 
752 Sánchez-Hernández, J., \& Cobo, F. (2012). Ontogenetic dietary shifts and food

753

754

755

756

757

758

759

760

761

762

763

764

765

766

767

768

769

770

771

772

773

774 selection of endemic Squalius carolitertii (Actinopterygii: Cypriniformes: Cyprinidae) in River Tormes, Central Spain, in summer. Acta Ichthyologica et Piscatoria, 42, 101-111. doi: 10.3750/AIP2011.42.2.03

Sánchez-Hernández, J., Cobo F., \& Amundsen, P.-A. (2015). Food web topology in high mountain lakes. PLoS One, 10, e0143016. doi: 10.1371/journal.pone.0143016

Sánchez-Hernández, J., Eloranta, A. P., Finstad, A. G., \& Amundsen, P.-A. (2017). Community structure affects trophic ontogeny in a predatory fish. Ecology and Evolution, 7, 358-367. doi: 10.1002/ece3.2600

Schmitz, O. J., Miller, J. R. B., Trainor, A. M., \& Abrahms, B. (2017). Toward a community ecology of landscapes: predicting multiple predator-prey interactions across geographic space. Ecology, 98, 2281-2292. doi: 10.1002/ecy.1916

Shurin, J. B., Borer, E. T., Seabloom, E. W., Anderson, K., Blanchette, C. A., Broitman, B., Cooper, S.D., \& Halpern, B. S. (2002). A cross-ecosystem comparison of the strength of trophic cascades. Ecology Letters, 5, 785-791. doi: 10.1046/j.14610248.2002.00381.x

Shurin, J. B., Gruner, D. S., \& Hillebrand, H. (2006). All wet or dried up? Real differences between aquatic and terrestrial food webs. Proceedings of the Royal Society of London. Series B, 273, 1-9. doi: 10.1098/rspb.2005.3377

Stanley, T., Doucouliagos, H., \& Ioannidis, J. (2017). Finding the power to reduce publication bias. Statistics in Medicine, 36, 1580-1598. doi: 10.1002/sim.7228 
775 Stergiou, K. I., \& Karpouzi, V. S. (2002). Feeding habits and trophic levels of

776 Mediterranean fish. Reviews in Fish Biology and Fisheries, 11, 217-254. doi:

777

778

779

780

781

782

783

784

785

786

787

788

789

790

791

792

793

794

795

796

797

798 10.1023/A: 1020556722822

Thompson, R. M., Hemberg, M., Starzomski, B. M., \& Shurin, J. B. (2007). Trophic levels and trophic tangles: the prevalence of omnivory in real food webs. Ecology, 88, 612-617. doi: 10.1890/05-1454

Vander Zanden, J. M., Cabana, G., \& Rasmussen, J. B. (1997). Comparing the trophic position of freshwater fish calculated using stable nitrogen isotope ratios $(\mathrm{d} 15 \mathrm{~N})$ and literature dietary data. Canadian Journal of Fisheries and Aquatic Sciences, 54, 1142-1158. doi: 10.1139/cjfas-54-5-1142

Vander Zanden, M. J., \& Rasmussen, J. B. (1996). A trophic position model of pelagic food webs: impact on contaminant biomagnification in lake trout. Ecological Monographs, 66, 451-477. doi: 10.2307/2963490

Winemiller, K. O., \& Leslie, M. A. (1992). Fish assemblages across a complex freshwater-marine ecotone. Environmental Biology of Fishes, 34, 29-50. doi: 10.1007/BF00004783

Wood, S. N. (2017). Generalized Additive Models: An Introduction with $R$ (wnd edition). London, Chapman and Hall/CRC.

Wootton, K. L. (2017). Omnivory and stability in freshwater habitats: Does theory match reality? Freshwater Biology, 62, 821-832. doi: 10.1111/fwb.12908

Zuur, A. F., Ieno, E. N., Walker, N. J., Saveliev, A. A., \& Smith, G. M. (2009). Mixed effects models and extensions in ecology with R. New York, Springer Science \& Business Media. 


\section{Table legends}

800 Table 1. Mean values ( \pm SE) of trophic position, omnivory and body size (maximum

801 length) with pairwise comparisons between systems according to feeding strategy, main

802 food type, habitat, geographic range and phylogeny. *Main food type is only shown for

803 predatory species and **habitat type is only shown for benthopelagic and demersal

804 species (see Methods). Significant values are marked in bold.

\begin{tabular}{|c|c|c|c|c|c|c|c|c|c|c|}
\hline & & \multicolumn{3}{|c|}{$\overline{M e a n} \pm \mathrm{SE}$} & \multicolumn{6}{|c|}{ Pairwise comparisons } \\
\hline & & \multirow{2}{*}{ Trophic position } & \multirow{2}{*}{ Omnivory } & \multirow{2}{*}{ Body size $(\mathrm{cm})$} & \multicolumn{2}{|c|}{ Trophic position } & \multicolumn{2}{|l|}{ Omnivory } & \multicolumn{2}{|l|}{$\mathrm{L}_{\max }$} \\
\hline & & & & & Mann-Whitney-Wilcoxon & Bonferroni & Mann-Whitney-Wilcoxon & Bonferroni & Mann-Whitney-Wilcoxon & Bonferroni \\
\hline \multicolumn{11}{|l|}{ Feeding strategies } \\
\hline Herbivory $(n=612)$ & $\begin{array}{c}\text { Freshwater } \\
\text { Marine }\end{array}$ & $\begin{array}{l}2.27 \pm 0.026 \\
2.24 \pm 0.018\end{array}$ & $\begin{array}{l}0.12 \pm 0.011 \\
0.09 \pm 0.007\end{array}$ & $\begin{array}{l}28.45 \pm 2.02 \\
21.20 \pm 0.92\end{array}$ & $W=38666, p=0.116$ & $p=0.116$ & $W=39480, p=0.036$ & $p=0.036$ & $W=48688, p<0.001$ & $p<0.001$ \\
\hline Filter-feeding $(n=703)$ & $\begin{array}{c}\text { Freshwater } \\
\text { Marine }\end{array}$ & $\begin{array}{l}3.05 \pm 0.045 \\
3.23 \pm 0.013\end{array}$ & $\begin{array}{l}0.33 \pm 0.015 \\
0.37 \pm 0.005\end{array}$ & $\begin{array}{l}22.21 \pm 2.51 \\
27.82 \pm 3.97\end{array}$ & $W=27039, p=0.001$ & $p=0.001$ & $W=28416, p=\mathbf{0 . 0 1 2}$ & $p=0.012$ & $W=32845, p=0.491$ & $p=0.491$ \\
\hline Predators $(n=4111)$ & $\begin{array}{c}\text { Freshwater } \\
\text { Marine }\end{array}$ & $\begin{array}{l}3.55 \pm 0.014 \\
3.73 \pm 0.008\end{array}$ & $\begin{array}{l}0.51 \pm 0.005 \\
0.54 \pm 0.003\end{array}$ & $\begin{array}{l}38.74 \pm 1.55 \\
61.02 \pm 1.24\end{array}$ & $W=1017400, p<0.001$ & $p<0.001$ & $W=1183600, p<0.001$ & $p<0.001$ & $W=1077100, p<0.001$ & $p<0.001$ \\
\hline \multicolumn{11}{|l|}{$\underline{\text { Main food type }}$} \\
\hline Zoobenthos $(n=28969)$ & $\begin{array}{c}\text { Freshwater } \\
\text { Marine }\end{array}$ & $\begin{array}{l}3.37 \pm 0.011 \\
3.53 \pm 0.007\end{array}$ & $\begin{array}{l}0.45 \pm 0.004 \\
0.48 \pm 0.003\end{array}$ & $\begin{array}{l}31.59 \pm 1.41 \\
42.49 \pm 0.83\end{array}$ & $W=465690, \boldsymbol{p}<\mathbf{0 . 0 0 1}$ & $p<0.001$ & $W=574290, \boldsymbol{p}<\mathbf{0 . 0 0 1}$ & $p<0.001$ & $W=571980, \boldsymbol{p}<\mathbf{0 . 0 0 1}$ & $p<0.001$ \\
\hline Nekton $(n=1226)$ & $\begin{array}{c}\text { Freshwater } \\
\text { Marine }\end{array}$ & $\begin{array}{l}4.10 \pm 0.019 \\
4.16 \pm 0.009\end{array}$ & $\begin{array}{l}0.70 \pm 0.006 \\
0.67 \pm 0.004\end{array}$ & $\begin{array}{c}60.31 \pm 4.29 \\
101.20 \pm 3.12\end{array}$ & $W=104470, p=0.099$ & $p=0.099$ & $W=128920, \boldsymbol{p}<\mathbf{0 . 0 0 1}$ & $p<0.001$ & $W=76337, \boldsymbol{p}<\mathbf{0 . 0 0 1}$ & $p<0.001$ \\
\hline \multicolumn{11}{|l|}{$\underline{\text { Habitat }{ }^{* *}}$} \\
\hline Benthopelagic $(n=1011)$ & $\begin{array}{c}\text { Freshwater } \\
\text { Marine }\end{array}$ & $\begin{array}{l}3.26 \pm 0.024 \\
3.69 \pm 0.031\end{array}$ & $\begin{array}{l}0.42 \pm 0.008 \\
0.52 \pm 0.011\end{array}$ & $\begin{array}{l}30.61 \pm 1.51 \\
76.04 \pm 5.24\end{array}$ & $W=53473, \boldsymbol{p}<\mathbf{0 . 0 0 1}$ & $p<0.001$ & $W=61054, p<0.001$ & $p<0.001$ & $W=41416, \boldsymbol{p}<\mathbf{0 . 0 0 1}$ & $p<0.001$ \\
\hline Demersal $(n=1740)$ & $\begin{array}{c}\text { Freshwater } \\
\text { Marine }\end{array}$ & $\begin{array}{l}3.37 \pm 0.027 \\
3.55 \pm 0.014\end{array}$ & $\begin{array}{l}0.45 \pm 0.009 \\
0.49 \pm 0.005\end{array}$ & $\begin{array}{l}43.98 \pm 2.32 \\
50.08 \pm 1.35\end{array}$ & $W=211160, \boldsymbol{p}<\mathbf{0 . 0 0 1}$ & $p<0.001$ & $W=241040, p=0.001$ & $p<0.001$ & $W=266300, p<0.001$ & $p<0.001$ \\
\hline \multicolumn{11}{|l|}{ Geographic range } \\
\hline Tropical $(n=3171)$ & $\begin{array}{c}\text { Freshwater } \\
\text { Marine }\end{array}$ & $\begin{array}{l}3.31 \pm 0.021 \\
3.39 \pm 0.015\end{array}$ & $\begin{array}{l}0.44 \pm 0.007 \\
0.44 \pm 0.005\end{array}$ & $\begin{array}{l}32.74 \pm 1.33 \\
40.68 \pm 1.02\end{array}$ & $W=880700, \boldsymbol{p}<\mathbf{0 . 0 0 1}$ & $p<0.001$ & $W=972120, p=0.804$ & $p=0.805$ & $W=934390, \boldsymbol{p}<\mathbf{0 . 0 0 1}$ & $p<0.001$ \\
\hline Subtropical $(n=1061)$ & $\begin{array}{c}\text { Freshwater } \\
\text { Marine }\end{array}$ & $\begin{array}{l}3.24 \pm 0.053 \\
3.66 \pm 0.018\end{array}$ & $\begin{array}{l}0.41 \pm 0.018 \\
0.52 \pm 0.006\end{array}$ & $\begin{array}{l}44.22 \pm 5.25 \\
75.17 \pm 3.44\end{array}$ & $W=23750, \boldsymbol{p}<\mathbf{0 . 0 0 1}$ & $p<0.001$ & $W=27927, \boldsymbol{p}<\mathbf{0 . 0 0 1}$ & $p<0.001$ & $W=35454, p<0.001$ & $p<0.001$ \\
\hline Temperate $(n=853)$ & $\begin{array}{c}\text { Freshwater } \\
\text { Marine }\end{array}$ & $\begin{array}{l}3.40 \pm 0.031 \\
3.61 \pm 0.019\end{array}$ & $\begin{array}{l}0.46 \pm 0.011 \\
0.51 \pm 0.007\end{array}$ & $\begin{array}{l}45.59 \pm 3.61 \\
59.58 \pm 2.93\end{array}$ & $W=41498, \boldsymbol{p}<0.001$ & $p<0.001$ & $W=44672, \boldsymbol{p}<0.001$ & $p<0.001$ & $W=57051, p<0.001$ & $p<0.001$ \\
\hline Polar $(n=100)$ & $\begin{array}{c}\text { Freshwater } \\
\text { Marine }\end{array}$ & $\begin{array}{l}3.51 \pm 0.232 \\
3.43 \pm 0.032\end{array}$ & $\begin{array}{l}0.50 \pm 0.028 \\
0.47 \pm 0.016\end{array}$ & $\begin{array}{l}26.25 \pm 6.58 \\
39.40 \pm 3.09\end{array}$ & $W=155, p=0.671$ & $p=0.664$ & $W=171, p=0.440$ & $p=0.433$ & $W=255, p=0.164$ & $p=0.162$ \\
\hline \multicolumn{11}{|l|}{$\underline{\text { Phylogeny }}$} \\
\hline Clupeiformes $(n=121)$ & $\begin{array}{c}\text { Freshwater } \\
\text { Marine }\end{array}$ & $\begin{array}{l}3.31 \pm 0.077 \\
3.18 \pm 0.055\end{array}$ & $\begin{array}{l}0.42 \pm 0.028 \\
0.37 \pm 0.018\end{array}$ & $\begin{array}{l}21.66 \pm 3.39 \\
25.63 \pm 1.97\end{array}$ & $W=1685.5, p=0.251$ & $p=0.250$ & $W=1712.5, p=0.191$ & $p=0.190$ & $W=1120.5, p=\mathbf{0 . 0 2 8}$ & $p=0.028$ \\
\hline Clupeidae $(n=80)$ & $\begin{array}{c}\text { Freshwater } \\
\text { Marine }\end{array}$ & $\begin{array}{l}3.19 \pm 0.084 \\
3.10 \pm 0.060\end{array}$ & $\begin{array}{l}0.39 \pm 0.027 \\
0.35 \pm 0.020\end{array}$ & $\begin{array}{l}16.30 \pm 2.73 \\
25.25 \pm 1.58\end{array}$ & $W=708.5, p=0.725$ & $p=0.721$ & $W=739, p=0.497$ & $p=0.494$ & $W=369.5, p=0.001$ & $p=0.001$ \\
\hline Osmeriformes $(n=38)$ & $\begin{array}{c}\text { Freshwater } \\
\text { Marine }\end{array}$ & $\begin{array}{l}3.31 \pm 0.084 \\
3.41 \pm 0.047\end{array}$ & $\begin{array}{l}0.42 \pm 0.037 \\
0.41 \pm 0.026\end{array}$ & $\begin{array}{l}40.11 \pm 27.36 \\
35.87 \pm 6.46\end{array}$ & $W=98, p=0.022$ & $p=0.021$ & $W=165.5, p=0.767$ & $p=0.755$ & $W=59, \boldsymbol{p}<\mathbf{0 . 0 0 1}$ & $p<0.001$ \\
\hline Perciformes $(n=3033)$ & $\begin{array}{c}\text { Freshwater } \\
\text { Marine }\end{array}$ & $\begin{array}{l}3.41 \pm 0.028 \\
3.35 \pm 0.014\end{array}$ & $\begin{array}{l}0.46 \pm 0.009 \\
0.43 \pm 0.004\end{array}$ & $\begin{array}{l}24.31 \pm 1.02 \\
42.52 \pm 0.99\end{array}$ & $W=686800, p=0.056$ & $p=0.055$ & $W=717230, \boldsymbol{p}<\mathbf{0 . 0 0 1}$ & $p<0.001$ & $W=551050, \boldsymbol{p}<\mathbf{0 . 0 0 1}$ & $p<0.001$ \\
\hline Gobiidae $(n=81)$ & $\begin{array}{c}\text { Freshwater } \\
\text { Marine }\end{array}$ & $\begin{array}{l}3.50 \pm 0.072 \\
3.25 \pm 0.045\end{array}$ & $\begin{array}{l}0.46 \pm 0.028 \\
0.38 \pm 0.022\end{array}$ & $\begin{array}{l}16.25 \pm 4.04 \\
11.77 \pm 1.28\end{array}$ & $W=718.5, p=0.006$ & $p=0.006$ & $W=609.5, p=0.176$ & $p=0.174$ & $W=650, p=0.665$ & $p=0.661$ \\
\hline Scorpaeniformes $(n=257)$ & $\begin{array}{c}\text { Freshwater } \\
\text { Marine }\end{array}$ & $\begin{array}{l}3.42 \pm 0.096 \\
3.67 \pm 0.023\end{array}$ & $\begin{array}{l}0.49 \pm 0.023 \\
0.55 \pm 0.009\end{array}$ & $\begin{array}{l}17.63 \pm 0.98 \\
35.97 \pm 1.59\end{array}$ & $W=523, p=0.025$ & $p=0.025$ & $W=607.5, p=0.075$ & $p=0.075$ & $W=1029.5, p=\mathbf{0 . 0 0 1}$ & $p<0.001$ \\
\hline Siluriformes $(n=257)$ & $\begin{array}{c}\text { Freshwater } \\
\text { Marine }\end{array}$ & $\begin{array}{l}3.42 \pm 0.039 \\
3.59 \pm 0.095\end{array}$ & $\begin{array}{l}0.49 \pm 0.013 \\
0.51 \pm 0.031\end{array}$ & $\begin{array}{l}55.27 \pm 4.34 \\
55.07 \pm 7.51\end{array}$ & $W=1810, p=0.081$ & $p=0.081$ & $W=2307.5, p=0.887$ & $p=0.886$ & $W=1988, p=0.410$ & $p=0.410$ \\
\hline Ariidae $(n=34)$ & $\begin{array}{c}\text { Freshwater } \\
\text { Marine }\end{array}$ & $\begin{array}{l}3.50 \pm 0.149 \\
3.68 \pm 0.082\end{array}$ & $\begin{array}{l}0.53 \pm 0.039 \\
0.53 \pm 0.032\end{array}$ & $\begin{array}{l}58.43 \pm 8.23 \\
53.53 \pm 8.10\end{array}$ & $W=99.5, p=0.365$ & $p=0.355$ & $W=115, p=0.758$ & $p=0.744$ & $W=162, p=0.451$ & $p=0.440$ \\
\hline
\end{tabular}

805 
806 Table 2. Summary table of the best model simulations for trophic position (Troph) and 807 omnivory index (OI) according to AIC values (summary table for the 10 best model 808 simulations is shown in Appendix 4). The parametric coefficients with significance 809 values are given for each variable. ${ }^{* *} p<0.001, * * p<0.01$ and $* p<0.05$.

810

\begin{tabular}{|c|c|c|c|c|c|c|c|c|}
\hline \multirow{2}{*}{ Variable } & \multirow{2}{*}{ Intercept } & Predictor & \multicolumn{5}{|c|}{ Smooth terms } & \multirow{2}{*}{$\begin{array}{c}\text { Model } \\
\text { statistics } \\
R^{2}\end{array}$} \\
\hline & & Body size & Ecosystem & $\begin{array}{c}\text { Feeding } \\
\text { strategies }\end{array}$ & $\begin{array}{c}\text { Main food } \\
\text { type }\end{array}$ & $\begin{array}{l}\text { Geographic } \\
\text { range }\end{array}$ & Habitat & \\
\hline Troph & $3.361 * * *$ & - & $5.340 * * *$ & $1.999 * * *$ & $1.997 * * *$ & 1.000 & - & 0.76 \\
\hline$O I$ & $0.458 * * *$ & $0.001 * *$ & $5.292 * * *$ & $1.997 * * *$ & $1.992 * * *$ & - & $1.544^{*}$ & 0.65 \\
\hline
\end{tabular}

811

812 


\section{Figure legends:}

814 Figure 1. Trophic position (Troph) and omnivory (omnivory index) of fishes according

815 to feeding strategies (Fil = filter-feeding, Her = herbivory, Pre = predatory), main food

816 type $(\mathrm{Nek}=$ nekton, $\mathrm{Zoo}=$ zoobenthos $)$, phylogeny $(\mathrm{Clu}=$ Clupeiformes, $\mathrm{Osm}=$

817 Osmeriformes, Per $=$ Perciformes, Sco $=$ Scorpaeniformes, Sil $=$ Siluriformes), and

818 ecosystem type $(\mathrm{F}=$ freshwater, $\mathrm{M}=$ marine$)$. Omnivory $=0$ (all feeding occurs at the 819 same troph).

820

821 Figure 2. Trophic position (Troph) and omnivory (omnivory index) of fishes according 822 to habitat type $(\mathrm{BD}=$ bathydemersal, $\mathrm{BP}=$ bathypelagic, $\mathrm{BeP}=$ benthopelagic, $\mathrm{D}=$ 823 demersal, $\mathrm{P}=$ pelagic, $\mathrm{PN}=$ pelagic-neritic, $\mathrm{PO}=$ pelagic-oceanic, and $\mathrm{R}=$ reef824 associated), geographic range (Tro $=$ tropical, $\mathrm{Sub}=$ subtropical, Tem $=$ temperate, $\mathrm{Pol}$ 825 = polar, and $\mathrm{Cos}=$ cosmopolitan $)$, and ecosystem type $(\mathrm{F}=$ freshwater, $\mathrm{M}=$ marine $)$. 826 Omnivory $=0$ (all feeding occurs at the same troph). 


\section{Data accessibility}

829 Data used in this study are available from FishBase (http://www.fishbase.org). Data

830 from the manuscript will be archived in the Figshare Digital Repository

831 (https://figshare.com/) on acceptance of the manuscript for publication.

832

833 Supporting information

834 List of items in the supporting information:

835 -Appendix 1. Information regarding how sample size varied between main food type, 836 habitat and geographic range.

837 -Appendix 2. List of orders and families incorporated into the study. Families are 838 grouped by type of ecosystem. The number of species per order or family is shown in 839 brackets.

840 -Appendix 3. Residual structure (GAMMs) of the best model simulations.

841 -Appendix 4. Summary table for the 10 best model simulations explaining the variation 842 of trophic position and omnivory in fishes. 

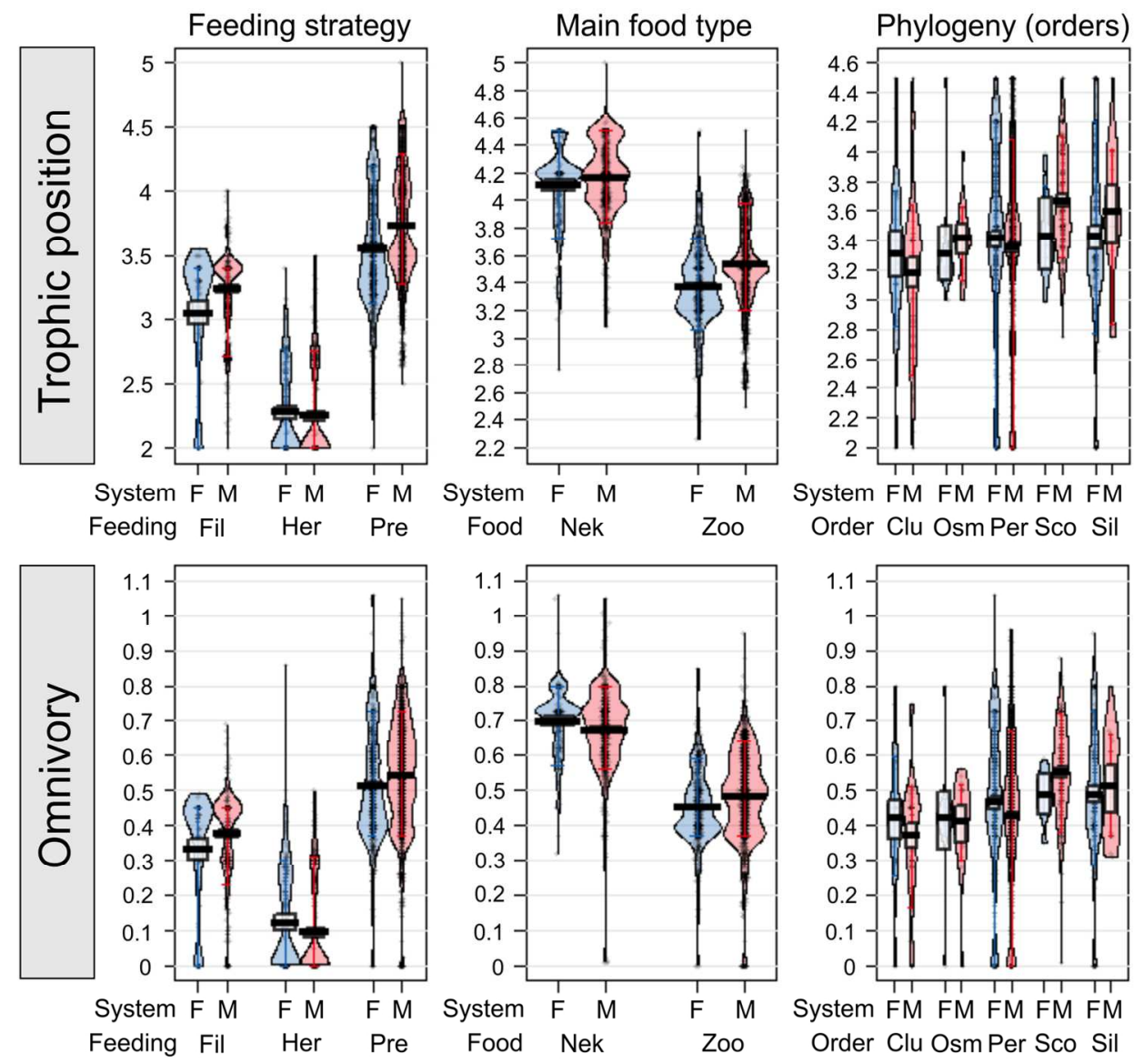

Figure 1. Trophic position (Troph) and omnivory (omnivory index) of fishes according to feeding strategies (Fil = filter-feeding, Her = herbivory, Pre = predatory), main food type (Nek = nekton, Zoo = zoobenthos), phylogeny $(\mathrm{Clu}=$ Clupeiformes, $\mathrm{Osm}=$ Osmeriformes, $\mathrm{Per}=$ Perciformes, $\mathrm{Sco}=$ Scorpaeniformes, $\mathrm{Sil}=$ Siluriformes), and ecosystem type $(F=$ freshwater, $M=$ marine). Omnivory $=0$ (all feeding occurs at the same troph). 

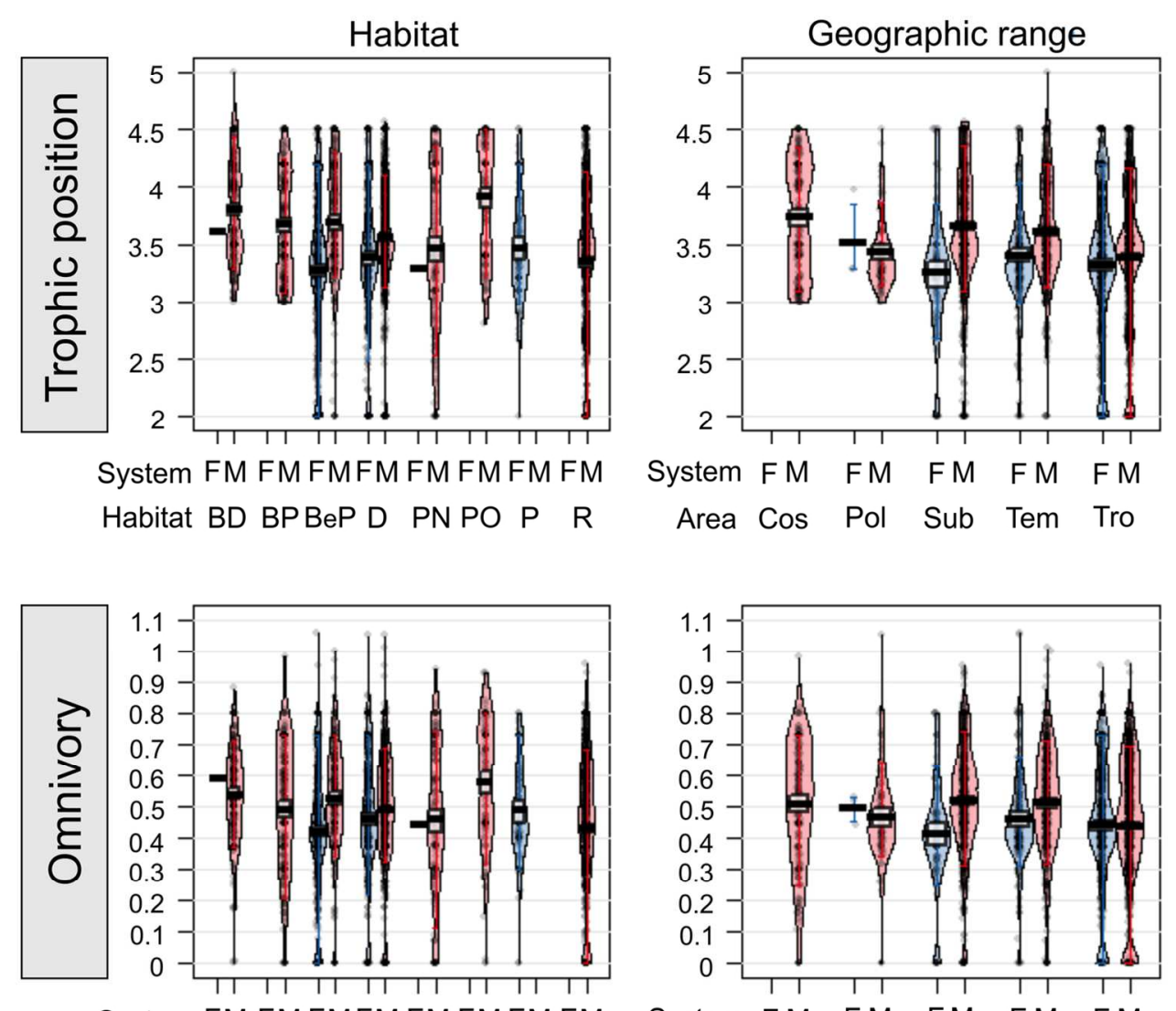

System FM FM FMFM FM FM FM FM Habitat BD BPBeP D PN PO P R

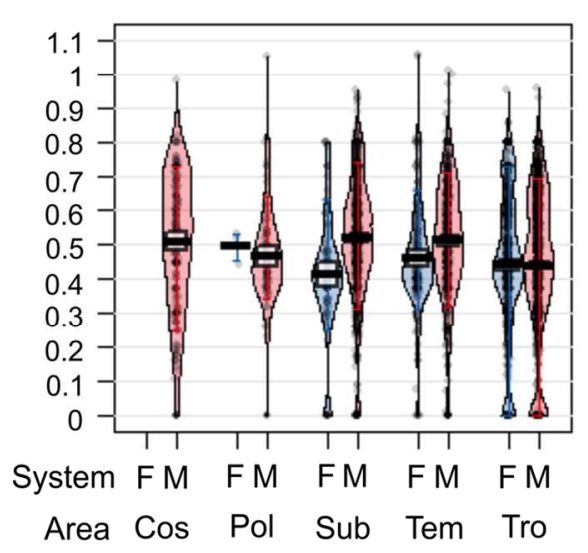

Figure 2. Trophic position (Troph) and omnivory (omnivory index) of fishes according to habitat type (BD = bathydemersal, $\mathrm{BP}=$ bathypelagic, $\mathrm{BeP}=$ benthopelagic, $\mathrm{D}=$ demersal, $\mathrm{P}=$ pelagic, $\mathrm{PN}=$ pelagic-neritic, $\mathrm{PO}=$ pelagic-oceanic, and $\mathrm{R}=$ reef-associated $)$, geographic range $($ Tro $=$ tropical, Sub $=$ subtropical, Tem $=$ temperate, $\mathrm{Pol}=$ polar, and $\mathrm{Cos}=$ cosmopolitan), and ecosystem type $(\mathrm{F}=$ freshwater, $\mathrm{M}=$ marine $)$. Omnivory $=0$ (all feeding occurs at the same troph). 